\title{
Europe should immediately implement the effective policy against the resurging pandemic
}

\author{
yoshiyasu takefuji ${ }^{1}$
}

${ }^{1}$ Affiliation not available

October 20, 2020

\begin{abstract}
Europe should immediately implement the effective policy based on isolating-all-at-risk strategy for mitigating the resurging pandemic.

TEXT

N. W. Ruktanonchai et al. assessed the impact of coordinated COVID-19 exit strategies across Europe (1). As shown in Fig.1 (2), the resurgence of deaths due to the COVID-19 can be observed in Europe so that the effective policy on isolating-all-at-risk strategy should be implemented as soon as possible for mitigating the pandemic. The effectiveness of the policy against the COVID-19 is justified by the number of deaths due to the COVID-19 (3,4). Since we have currently no vaccine and effective therapy against the COVID-19, we have one and only one policy based on isolating-all-at-risk strategy (4). Why not implement the real-time digital defense immediately in Europe. Remember that more than 1000 persons in Europe are killed daily due to the COVID-19 as of Oct. 19 in 2020.

Conclusion

Expert scientists should know what we should do for mitigating the resurging pandemic, regardless of politics.
\end{abstract}




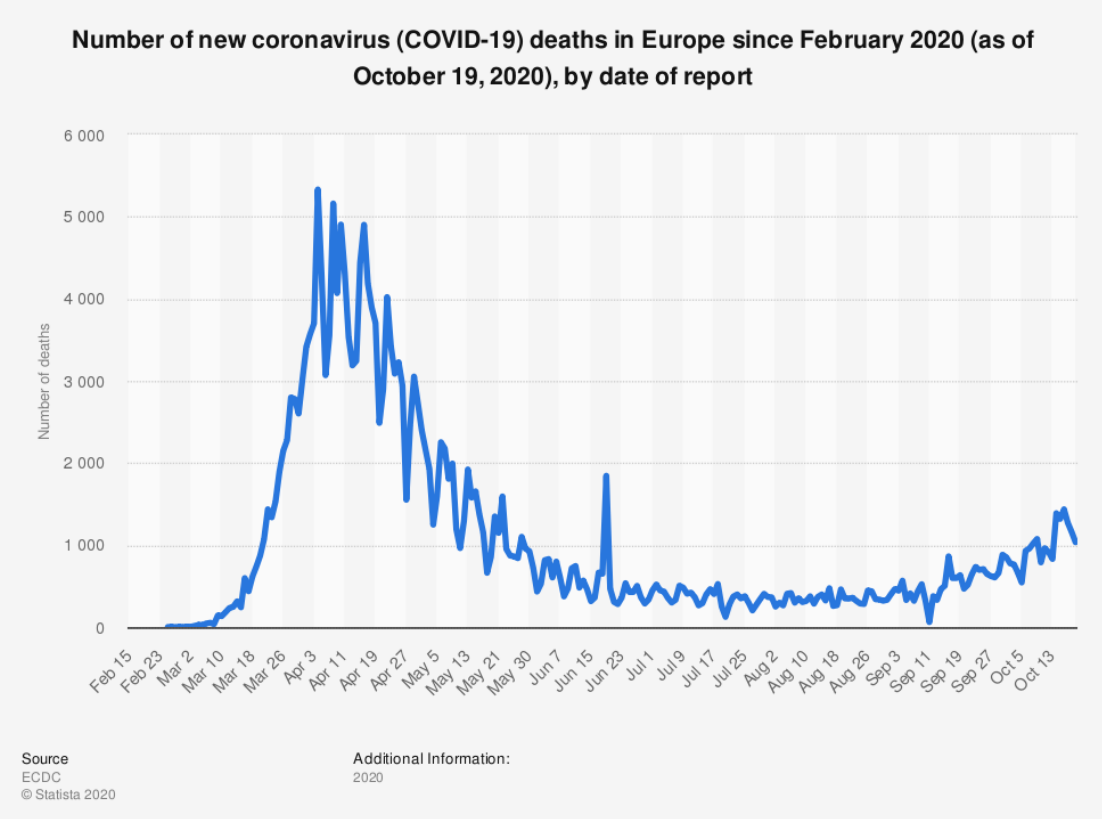

Fig.1 as of Oct. 19 in 2020 is at the following site:

https://www.statista.com/statistics/1102288/coronavirus-deaths-development-europe/

References:

1. N. W. Ruktanonchai et al., Assessing the impact of coordinated COVID-19 exit strategies across Europe, Science 18 Sep 2020: Vol. 369, Issue 6510, pp. 1465-1470 DOI: 10.1126/science.abc5096

2.https://www.statista.com/statistics/1102288/coronavirus-deaths-development-europe/

3.https://www.worldometers.info/coronavirus/country/taiwan/

4.Wang CJ, Ng CY, Brook RH. Response to COVID-19 in Taiwan: Big Data Analytics, New Technology, and Proactive Testing. JAMA.2020;323(14):1341-1342. doi:10.1001/jama.2020.3151 